\section{Interplay between hydrophilic and hydrophobic interactions in the self-assembly of a gemini amphiphilic pseudopeptide: from nano-spheres to hydrogels $\dagger$}

\author{
Jenifer Rubio, ${ }^{a}$ Ignacio Alfonso, ${ }^{* b}$ M. Isabel Burguete ${ }^{a}$ and Santiago V. Luis ${ }^{* a}$ \\ Received 17th November 2011, Accepted 16th December 2011 \\ DOI: $10.1039 / \mathrm{c} 2 \mathrm{cc17153h}$
}

The formation of soluble nano-spheres or stable hydrogels through the self-assembling of a simple gemini amphiphilic pseudopeptide can be controlled by the tuning of the hydrophilic/ hydrophobic interactions in aqueous medium.

The aggregation of peptide-like molecules is an extremely important process, closely related to serious diseases like priondiseases ${ }^{1}$ and other neurodegenerative problems. ${ }^{2}$ However, a full understanding of the mechanisms at the molecular level is still far from being achieved. These aggregation processes have been related to the misfolding of certain peptides, thus connecting folding/unfolding and self-assembling of biological systems. On the other hand, the hierarchical and controlled self-assembly of simple molecules has attracted much attention in the last decade, as the bottom-up approach to nanotechnology. ${ }^{3}$ Initially inspired by nature and encouraged by previous results, ${ }^{4}$ we designed a family of gemini amphiphilic pseudopeptides (GAPs), which are simple $C_{2}$ symmetric molecules built from two amino acids connected at their acid ends by a flexible spacer, and bearing two hydrophobic tails at both extremes. ${ }^{5,6} \mathrm{We}$ found that these simple molecules are able to self-assemble into different nanostructures through the cooperative action of polar (H-bonding and dipole-dipole) and non-polar (van der Waals) intermolecular interactions. ${ }^{7}$ Moreover, those GAPs showing specific structural features behaved as stimulus dependent systems, forming amorphous materials in chloroform, fibers in methanol or aqueous methanol at neutral or basic $\mathrm{pH}$, while vesicles when protonated in this medium. ${ }^{6}$ After studying the processes with different techniques, we proposed a structural model for the observed properties, based on the flexibility of the molecules that allows them to fold and unfold upon the action of external chemical forces. ${ }^{6}$ Following the same structural design, we envisioned the preparation of a second generation

\footnotetext{
${ }^{a}$ Departamento de Química Inorgánica y Orgánica,

Universidad Jaume I, Avenida Sos Baynat, s/n, Castellón, Spain.

E-mail: luiss@qio.uji.es; Fax: + 34 964728214; Tel: + 34964728239

${ }^{b}$ Departamento de Química Biológica y Modelización Molecular,

IQAC-CSIC, Jordi Girona 18-26, Barcelona, Spain.

E-mail: ignacio.alfonso@iqac.csic.es; Fax: +34 932045904;

Tel: +34934006100

$\dagger$ Electronic supplementary information (ESI) available: Full characterization (NMR, ESI-MS, ATR- FTIR, SEM, TEM, gelation studies) and experimental details. See DOI: $10.1039 / \mathrm{c} 2 \mathrm{cc} 17153 \mathrm{~h}$
}

of GAPs that were more soluble in water, ${ }^{8}$ since this is the most interesting medium for studies of biological relevance. Accordingly, we hypothesized that a GAP bearing a nitrogen atom in the middle of the central spacer should be a reasonable structural motif (1 in Scheme 1) for the improvement of the aqueous solubility. Within our model, this spacer is responsible for the folding-unfolding process and belongs to the water-exposed moiety in the vesicular assembly of the folded conformation in very polar environments (Scheme 1). For this design, we kept the valine and the decyloxybenzyl moieties because they were the most efficient fragments in our initial systems. ${ }^{6}$

The synthesis of $\mathbf{1}$ was accomplished following the previously reported general synthetic procedure and is described in detail in the ESI. $\dagger^{5,6}$ The first satisfying observation was the apparently good solubility of $\mathbf{1}$ in pure water at neutral and, especially, at acidic $\mathrm{pH}$. However, fluorescence studies in pure water using pyrene as a probe rendered a critical aggregation concentration (CAC, Fig. S6, ESI $\dagger$ ) of $5.7 \times 10^{-5} \mathrm{M}$ at pH 2.7 and $1.4 \times 10^{-5}$ at $\mathrm{pH} 7 .{ }^{9}$ On the other hand, the ${ }^{1} \mathrm{H}$ NMR spectrum of $\mathbf{1}$ in $\mathrm{D}_{2} \mathrm{O}$ $(500 \mathrm{MHz}, 3 \mathrm{mM}$ of $\mathbf{1}$ at acidic pH, far above the CAC, Fig. S2, ESI $\dagger$ ) displayed very broad signals, most likely due to fast spin-spin cross relaxation. ${ }^{10}$ Accordingly, the NOESY spectrum (Fig. S3, ESI $\dagger$ ) showed large negative peaks between all the proton signals, implying the efficient spin diffusion and a very slow tumbling time in solution. Actually, DOSY NMR spectroscopy (Fig. S5, ESI $\dagger$ ) rendered a self-diffusion rate of

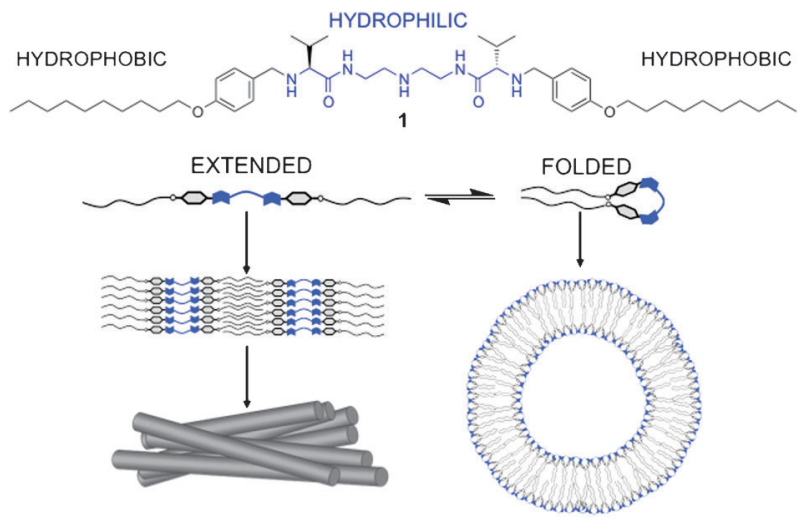

Scheme 1 Chemical structure of 1 and schematic representation of the proposed assembly of extended or folded conformations of $\mathbf{1}$ into fibers and vesicles, respectively. 


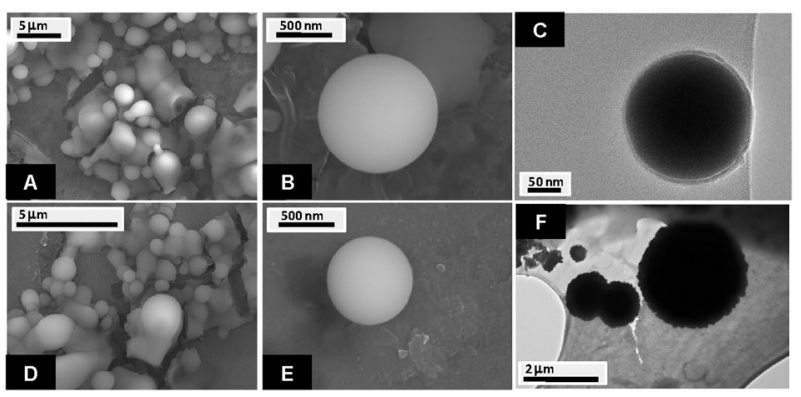

Fig. 1 SEM (A, B, D and E) and TEM (C and F) micrographs of 1 in pure water at $\mathrm{pH} 7(\mathrm{~A}-\mathrm{C})$ and $\mathrm{pH} 2.3(\mathrm{D}-\mathrm{F})$.

$2.8 \pm 0.3 \times 10^{-11} \mathrm{~m}^{2} \mathrm{~s}^{-1}$, which corresponds to an apparent hydrodynamic radius of $\sim 7.1 \mathrm{~nm}$ (more than ten times larger than the one expected for a single molecule of 1). All these observations supported the presence of relatively large aggregates of $\mathbf{1}$ in aqueous solution. Scanning electron microscopy (SEM) and transmission electron microscopy (TEM) showed the formation of spherical nanostructures (Fig. 1 and Fig. S7-S9, ESI $†$ ). Analysing the SEM/TEM images, these vesicles are prone to undergo deformation and fusion processes. Besides, the different sizes observed in the evaporated samples for SEM/TEM reflect the soft matter nature of these supramolecular assemblies. Attenuated total reflectance (ATR) FT-IR spectroscopy of these vesicles showed a band at $2852 \mathrm{~cm}^{-1}$ assigned to the symmetric $\mathrm{C}-\mathrm{H}$ stretching vibrational mode, suggesting the role of the van der Waals contacts between the hydrophobic tails in the formation of the nanostructures. ${ }^{6,11}$ All these data confirmed the success of our initial design toward the formation of vesicles in biologically relevant environments, namely pure water at neutral or acidic $\mathrm{pH}$.

The nano-spheres formation occurs through the assembly of folded $\mathbf{1}$ in a gemini surfactant-like fashion (Scheme 1). We hypothesized that the presence of an organic co-solvent would maintain the GAP in an extended conformation, where the hydrophobic and $\mathrm{H}$-bonding intermolecular interactions could operate in a preferred direction, ${ }^{12}$ leading to the formation of nanofibers upon self-assembly. The ${ }^{1} \mathrm{H}$ NMR spectrum of $\mathbf{1}$ in $\mathrm{CD}_{3} \mathrm{OD}$ (Fig. S2, ESI $\dagger$ ) showed well-defined signals, suggesting the efficient solvation of $\mathbf{1}$ in a flexible unfolded conformation, and the absence of aggregation at the $\mathrm{mM}$ concentration. Surprisingly, the addition of water produced the spontaneous formation of a stable gel within minutes at room temperature (Fig. 2A and movie in the ESI $\dagger$ ) ${ }^{13}$ Interestingly, gelation does not require the previous heating of $\mathbf{1}$ with the solvent mixtures, as needed for most gelators. The systematic study of this process showed that 1 spontaneously and rapidly forms stable roomtemperature hydrogels ${ }^{14,15}$ under a wide range of experimental conditions from 30-90\% aqueous methanol (Table 1). For instance, at $2 \mathrm{wt} \%$ of $\mathbf{1}$, room temperature supramolecular hydrogels can be formed from $70: 30$ to $10: 90 \mathrm{MeOH}: \mathrm{H}_{2} \mathrm{O}$ mixtures. On the other hand, for $c a .1: 1 \mathrm{MeOH}: \mathrm{H}_{2} \mathrm{O}$ mixtures, the minimum concentration of $\mathbf{1}$ to form a stable gel is as low as $0.1 \mathrm{wt} \%$. Additionally, the microscopic morphology of the hydrogel was studied with SEM and TEM (Fig. 2A and Fig. S7 and S10, ESI $\dagger$ ). The dried gel showed the presence of an interpenetrated network of nanofibers, which can be rationalized analysing the experimental data. The compound $\mathbf{1}$ is well solvated in $\mathrm{MeOH}$ solution and thus, an extended
A
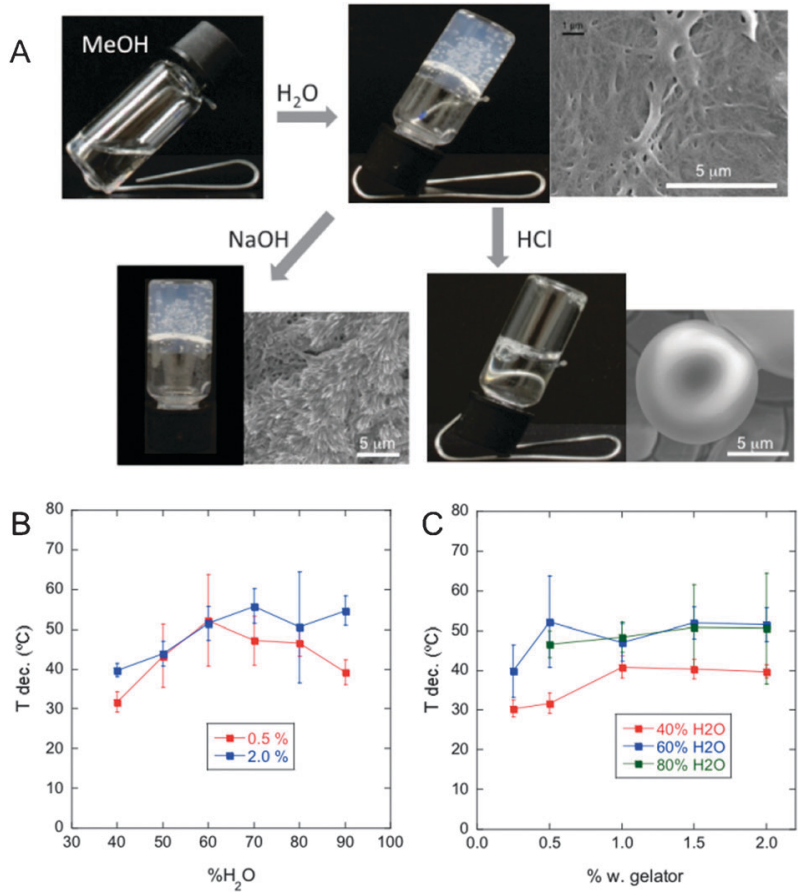

Fig. 2 (A) Formation of a hydrogel from 1 and the effect of the $\mathrm{pH}$, with the corresponding microscopic morphology (SEM). (B and C) Plots of the temperatures of gel disassembly as a function of (B) solvent and (C) gelator content. Error bars represent the temperature intervals for the observed disassembly with the symbols at the midpoint of the transitions.

Table 1 Gelation properties of $\mathbf{1}$ as a function of the gelator content $\left(\mathrm{wt} \%\right.$ ) and the $\mathrm{MeOH}: \mathrm{H}_{2} \mathrm{O}$ proportion

\begin{tabular}{llllllll}
\hline & $\mathrm{MeOH}: \mathrm{H}_{2} \mathrm{O}$ & $0.1 \%$ & $0.25 \%$ & $0.5 \%$ & $1.0 \%$ & $1.5 \%$ & $2.0 \%$ \\
\hline 1 & $80: 20$ & - & $\mathrm{S}$ & $\mathrm{S}$ & $\mathrm{S}$ & $\mathrm{S}$ & $\mathrm{S}$ \\
2 & $70: 30$ & - & $\mathrm{S}$ & $\mathrm{S}$ & $\mathrm{wG}$ & $\mathrm{wG}$ & $\mathrm{G}$ \\
3 & $60: 40$ & - & $\mathrm{WG}$ & $\mathrm{G}$ & $\mathrm{G}$ & $\mathrm{G}$ & $\mathrm{G}$ \\
4 & $50: 50$ & $\mathrm{wG}$ & $\mathrm{G}$ & $\mathrm{G}$ & $\mathrm{G}$ & $\mathrm{G}$ & $\mathrm{G}$ \\
5 & $40: 60$ & $\mathrm{WG}$ & $\mathrm{G}$ & $\mathrm{G}$ & $\mathrm{G}$ & $\mathrm{G}$ & $\mathrm{G}$ \\
6 & $30: 70$ & - & $\mathrm{S}$ & $\mathrm{G}$ & $\mathrm{G}$ & $\mathrm{G}$ & $\mathrm{G}$ \\
7 & $20: 80$ & - & $\mathrm{S}$ & $\mathrm{G}$ & $\mathrm{G}$ & $\mathrm{G}$ & $\mathrm{G}$ \\
8 & $10: 90$ & - & $\mathrm{S}$ & $\mathrm{wG}$ & $\mathrm{G}$ & $\mathrm{G}$ & $\mathrm{G}$ \\
9 & $0: 100$ & - & $\mathrm{S}$ & $\mathrm{S}$ & $\mathrm{S}$ & $\mathrm{S}$ & $\mathrm{S}$
\end{tabular}

S: soluble, wG: weak gel, G: gel.

flexible conformation could be proposed, as suggested by NMR. The addition of water triggered the aggregation of the molecules of $\mathbf{1}$ through the van der Waals contacts between the hydrophobic tails. Concomitantly, the central polar pseudopeptidic moiety would set intermolecular H-bonding interactions, which would produce a preferred directionality for the self-assembly, rendering the observed fibrilar morphology. The interpenetrated network thus formed is able to trap the solvent molecules, finally rendering a stable gel. The main intermolecular interactions implicated in the assembly of the hydrogel were supported by ATR FT-IR spectroscopy. The bands at 3289 and $3315 \mathrm{~cm}^{-1}$ implied the presence of $\mathrm{H}$-bonded $\mathrm{N}-\mathrm{H}$ amide groups, while the symmetric $\mathrm{C}-\mathrm{H}$ stretching at $2851 \mathrm{~cm}^{-1}$ indicated a hydrophobic packing of the aliphatic chains. ${ }^{6,11}$ Very interestingly, the addition of $\mathrm{MeOH}$ to a solution of compound $\mathbf{1}$ in water failed to form 
a gel, even after intensive heating or sonication. TEM images of these solutions showed the presence of mixed spherical and fibrilar nanostructures (Fig. S10, ESI $\dagger$ ). This implies that the vesicles formed in pure water by the assembly of the folded GAP are partially protected from the unfolding action of the $\mathrm{MeOH}$. These observations suggested that the formation of the hydrogel is a result of a delicate interplay between hydrophobic and hydrophilic intermolecular interactions, which are possible only in the unfolded conformation of $\mathbf{1} .^{12,15,16}$

The thermal stability of the supramolecular hydrogel was also studied as a function of the gelator content and the amount of water added to the $\mathrm{MeOH}$ (Fig. 2B and C). Interestingly, the stability of the gel depended on both variables, being maxima at different ratios for every case. The suitable comparison of the plots suggests that the stability of the gel is more sensitive to changes in the solvent composition (Fig. 2B) than to the gelator content (Fig. 2C). Besides, for the most suitable $\mathrm{MeOH}$ : water ratios, the stability of the hydrogels remains constant at different gelator contents above $0.5 \% \mathrm{w} / \mathrm{v}$ (see Fig. 2C, blue and green plots). These results suggest that the hydrogel of $\mathbf{1}$ is formed by the synergic action of hydrophobic and H-bonding interactions and thus, a possible enthalpy/entropy compensation effect could be operating, leading to some irregular trends in the temperature dependence. The hydrogel of $\mathbf{1}$ can be also disassembled by changes in the $\mathrm{pH}$ (Fig. 2A). Thus, simple addition of an acid $(\mathrm{HCl})$ to the gel produced the transition to a solution (see Fig. S21†, ESI $\dagger$, for snapshots of the acid-promoted gel disassembly) despite the hydrogel being perfectly stable to the addition of a base (Fig. 2A). The SEM images of the disassembled gel in acidic medium showed the presence of large microspheres, suggesting a cationic surfactant-like behavior (Fig. 2A). On the other hand, according to the stability of the gel in basic medium, its SEM micrographs still showed a fibrilar network (Fig. 2A). Thus, the simple compound $\mathbf{1}$ can be considered as a stimulus-responsive (temperature, $\mathrm{pH}$ and solvent) room-temperature hydrogelator.

In summary, we report the efficient design of a simple GAP able to self-assemble in aqueous medium. In pure water, $\mathbf{1}$ self-assembles into vesicles at both acidic and neutral $\mathrm{pH}$. The addition of water to a methanolic solution of $\mathbf{1}$ spontaneously forms room-temperature stable hydrogels, which can be disassembled by heating or protonation. Very importantly, the alcoholic co-solvent needed for the formation of the hydrogel can be substituted by the more bio-compatible EtOH. $\dagger$ For instance, compound $\mathbf{1}$ at $1 \% \mathrm{wt} / \mathrm{v}$ concentration forms a stable gel $\left(T_{\mathrm{g}}=53{ }^{\circ} \mathrm{C}\right)$ in $90: 10 \mathrm{H}_{2} \mathrm{O}: \mathrm{EtOH}$, a mixture commonly used for drug formulation and biological assays (see ESI $\dagger$ ) and thus foreseeing the potential bionanotechnological applications of $\mathbf{1}$.

This work was supported by the Spanish MICINN (CTQ2009-14366-C02) and UJI-Bancaixa (P1-1B-2009-59). J. R. thanks MICINN for personal financial support (FPU fellowship).

\section{Notes and references}

1 K. R. Cho, Y. Huang, S. Yu, S. Yin, M. Plomp, S. R. Qiu, R. Lakshminarayanan, J. Moradian-Oldak, M. S. Sy and J. J. De Yoreo, J. Am. Chem. Soc., 2011, 133, 8586; S. B. Prusiner, Proc. Natl. Acad. Sci. U. S. A., 1998, 95, 13363; B. Caughey and P. T. Lansbury, Annu. Rev. Neurosci., 2003, 26, 267; L. Y. L. Lee and R. P. Y. Chen, J. Am. Chem. Soc., 2007, 129, 1644; J. P. Taylor, J. Hardy and K. H. Fischbeck, Science, 2002, 296, 1991.

2 P. T. Lansbury and H. A. Lashuel, Nature, 2006, 443, 774.

3 G. M. Whitesides and B. Grzybowski, Science, 2002, 295, 2418; J. M. Lehn, Science, 2002, 295, 2400; L. P. Hernández-Eguía, R. J. Brea, L. Castedo, P. Ballester and J. R. Granja, Chem.-Eur. J., 2011, 17, 1220; E. Gorrea, P. Nolis, E. Torres, E. Da Silva, D. B. Amabilino, V. Branchadell and R. M. Ortuño, Chem.-Eur. J., 2011, 17, 4588.

4 I. Alfonso, M. Bru, M. I. Burguete, E. García-Verdugo and S. V. Luis, Chem.-Eur. J., 2010, 16, 1246.

5 J. Rubio, I. Alfonso, M. Bru, M. I. Burguete and S. V. Luis, Tetrahedron Lett., 2010, 51, 5861.

6 J. Rubio, I. Alfonso, M. I. Burguete and S. V. Luis, Soft Matter, 2011, 7, 10737.

7 S. Cavalli, F. Albericio and A. Kros, Chem. Soc. Rev., 2010, 39, 241; E. Gazit, Chem. Soc. Rev., 2007, 36, 1263; S. Ghosh and S. Verma, Tetrahedron, 2008, 64, 6202; I. W. Hamley, Soft Matter, 2011, 7, 4122; M. Surin, P. G. A. Janssen, R. Lazzaroni, P. Leclère, E. W. Meijer and A. P. H. J. Schenning, Adv. Mater., 2009, 21, 1126; G. P. Spada, S. Lena, S. Masiero, S. Pieraccini, M. Surin and P. Samorì, Adv. Mater., 2008, 20, 2433; M. J. Krysmann, V. Castelletto, J. E. McKendrick, L. A. Clifton, I. W. Hamley, P. J. F. Harris and S. M. King, Langmuir, 2008, 24, 8158; V. Castelletto and I. W. Hamley, Biophys. Chem., 2009, 141, 169; R. J. Brea, C. Reiriz and J. R. Granja, Chem. Soc. Rev., 2010, 39, 1448.

8 J. Rubio, M. A. Izquierdo, M. I. Burguete, F. Galindo and S. V. Luis, Nanoscale, 2011, 3, 3613.

9 K. S. Sharma, C. Rodgers, R. M. Palepu and A. K. Rakshit, J. Colloid Interface Sci., 2003, 268, 482; T. Yoshimura, T. Ichinokawa, M. Kaji and K. Esumi, Colloids Surf., A, 2006, 273, 208.

10 S. P. Brown and H. W. Spiess, Chem. Rev., 2001, 101, 4125.

11 M. C. Hull, L. R. Cambrea and J. S. Hovis, Anal. Chem., 2005, 77, 6096.

12 S. Han, S. Cao, Y. Wang, J. Wang, D. Xia, H. Xu, X. Zhao and J. R. Lu, Chem.-Eur. J., 2011, 17, 13095.

13 M. Suzuki, Y. Nakajima, M. Yumoto, M. Kimura, H. Shirai and K. Hanabusa, Org. Biomol. Chem., 2004, 2, 1155; M. Suzuki, M. Yumoto, H. Shirai and K. Hanabusa, Chem.-Eur. J., 2008, 14, 2133; M. Suzuki and K. Hanabusa, Chem. Soc. Rev., 2009, 38, 967; A. Popov, M. B. Hickey, R. Hiremath, M. Peterson, P. Ratanabanangkoon, M. Rizzolio, S. Waggener and Y. Zimenkov, Pharm. Res., 2011, 28, 2556.

14 K. L. Liu, Z. Zhang and J. Li, Soft Matter, 2011, 7, 11290; J. Zhang, D.-S. Guo, L.-H. Wang, Z. Wang and Y. Liu, Soft Matter, 2011, 7, 1756; M. de Loos, B. L. Feringa and J. H. van Esch, Eur. J. Org. Chem., 2005, 3615; G. Cheng, V. Castelletto, R. R. Jones, C. J. Connon and I. W. Hamley, Soft Matter, 2011, 7, 1326; Y. Kuang, Y. Gao and B. Xu, Chem. Commun., 2011, 47, 12625; J. W. Sadownik, J. Leckie and R. V. Ulijn, Chem. Commun., 2011, 47, 728; W. Helen, P. de Leonardis, R. V. Ulijn, J. Gough and N. Tirelli, Soft Matter, 2011, 7, 1732; L. S. Birchall, S. Roy, V. Jayawarna, M. Hughes, E. Irvine, G. T. Okorogheye, N. Saudi, E. de Santis, T. Tuttle, A. A. Edwards and R. V. Ulijn, Chem. Sci., 2011, 2, 1349; M. Zhou, A. M. Smith, A. K. Das, N. W. Hodson, R. F. Collins, R. V. Ulijn and J. E. Gough, Biomaterials, 2009, 30, 2523.

15 L. A. Estroff and A. D. Hamilton, Chem. Rev., 2004, 104, 1201.

16 F. Ouhib, M. Raynal, B. Jouvelet, B. Isare and L. Bouteiller, Chem. Commun., 2011, 47, 10683. 